commendably few in an extremely well-produced and fully illustrated book which does eredit to both author and publisher. The sole drawback is the price, which it is hoped will prevent no institution from adding this book to its library. Marine biologists in general should buy it if they can, but in any event should most certainly read it.

C. M. YONGE

\section{GEOGRAPHICAL CLIMATOLOGY}

The Climate of New Zealand

A Geographic Survey. By B. J. Garnier. Pp. $191+12$ plates. (London : Edward Arnold (Publishers), Ltd., 1958.) 70s. net.

7 HIS superbly produced and distinctly expensive account of the principal features of the climate of New Zealand is derived in the main from numerous papers in scientific journals. Prof. B. J. Garnier, formerly of Otago and now at Ibadan, asks his readers to regard the volume primarily as an exposition of an important aspect of the country's geography and secondarily as an attempt to show how studies in systematic geography may make their particular contribution to the field of learning.

Like many geographers, he is evidently rather conscious of his subject and the occasional lapses into the jargon of geography are tiresome. "The overall slimatic picture of eastern North Island is one in which some diversity is held together in a framework of common distinguishing elements . . . a remarkable quality of the area as a geographic entity is the way this pattern is repeated by other features" (p. 107) will be well understood by students who have been subjected to this sort of thing, but if they want to know about the climate they may still refer with profit to Kidson's ten beautifully concise pages in The Quarterly Journal of The Royal Meteorological Society for 1937. Phrases such as "As its name implies, northern New Zealand is the most northerly of the climatic regions" (p. 71); an "influx of influences" (p. 142) are infelicitous. Fortunately, like the southerly rainstorms, these affectations do not last long. There are many agreeable descriptive passages, and in a work on climate the many references to the physical background and the regional characteristics of the vegetation and soil are most welcome; for example, the admirable paragraphs of plant geography on p. 130. The illustration of a summer cold wave is excellent (pp. 118-9).

Beginning with a broad survey of New Zealand's climatic qualities and a discussion of how these have been produced by the combined effect of its position and physiography, the author then defines his climatic regions and in nine chapters discusses their characteristics. The splendidly chosen landscape photographs are a most attractive feature; maps and diagrams abound; synoptic situations and monthly sequences of daily maxima and minima are well displayed; there are useful tables, an extensive bibliography and an index. With its fine assemblage of references, this work is perhaps to be regarded as a regional geography rather than a text on climate; for the present reviewer could find no information about the absolute extremes of temperature, no clear definition of the snow-line, no comment about the marginal qualities of Mt. Egmont, nothing on the climate of Stewart Island; no comment on the astonishing freedom from screen frost at Wellington (p. 170) which, incidentally, makes the averages on p. 169 look a little odd. For the British reader there is no clear indication of how often snow either falls or lies ; no map locating the stations; no detail about the frequency of thunderstorms. To say that conditions of permanent frost prevail on the high summits in North Island (p. 126) begs the question. Estimated lapse-rates of temperature in Appendix $A$ are not related to upperair data; and we hear nothing about the extent, if any, of climatic fluctuation in recent times. Rainfall reliability and also evapo-transpiration, a concern of many geographers, receive useful notice. To the regional geographer studying New Zealand as a whole this book, with its abundance of references, extracts, tables and maps, will have many virtues. It is costly, but can be a useful and indeed desirable acquisition to a library.

Gordon Manley

\section{TROUBLED WATERS}

An Introduction to Fluid Dynamics

By Dr. F. J. Bayley. Pp. viii +215 . (London : George Allen and Unwin, Ltd., 1958.) 28s. net.

An Introduction to Fluid Dynamics

By Prof. G. Temple. Pp. xi +195. (Oxford : Clarendon Press; London: Oxford University Press, 1958.) 25s. net.

Proceedings of the Fifth Midwestern Conference on Fluid Mechanics

Held at the University of Michigan, April 1 and 2, 1957. Edited by Prof. A. M. Kuethe. Pp. viii +388 . (Ann Arbor, Michigan : University of Michigan Press, 1957. Published for The Engineering Research Institute, Ann Arbor.) 8 dollars.

THE three volumes under review cater for different sections of the scientific community. Dr. Bayley aims at helping undergraduates in the engineering faculties while Prof. Temple's work is intended primarily for students reading honours mathematics or physics. The proceedings of the Fifth Midwestern Conference on Fluid Mechanics will appeal mainly to the research worker.

The introduction to fluid mechanics provided by Dr. Bayley is unsatisfactory. He has tried to write a simple book covering a wide field. This is extremely difficult to do, especially in two hundred pages, for it demands terse, lucid instruction. Unfortunately in this book the insistence on brevity has led to many vague statements and errors of omission. For example, the paragraph on units will do more to confuse than illuminate the situation. Such a text should surely start with a clear explanation of the three systems of engineering units in current usage and the relations between them. The chapter on fluids at rest contains no mention of floating bodies, and the presentation of the immensely powerful momentum equation is quite inadequate. Moreover, the compressible form of Bernoulli's equation is derived using $p=k \rho \gamma$. This can easily lead students to believe that the equation holds only for this type of flow. Later in the book Dr. Bayley does present the general energy equation both simply and accurately.

Dimensional analysis receives the prominence it deserves and the principle is demonstrated in a number of well-chosen examples. The most successful chapters deal with pipe flow, channel flow and fluid machinery, but the discussion of flow over immersed bodies is poor. The role of viscosity in the production 